\title{
Fungicide modes of action and resistance in downy mildews
}

\author{
Ulrich Gisi • Helge Sierotzki
}

Received: 24 September 2007 / Accepted: 11 February 2008 / Published online: 9 April 2008

(C) KNPV 2008

\begin{abstract}
Among oomycetes, Plasmopara viticola on grape and Phytophthora infestans on potato are agronomically the most important pathogens requiring control measures to avoid crop losses. Several chemical classes of fungicides are available with different properties in systemicity, specificity, duration of activity and risk of resistance. The major site-specific fungicides are the Quinone outside inhibitors (QoIs; e.g. azoxystrobin), phenylamides (e.g. mefenoxam), carboxylic acid amides (CAAs; e.g. dimethomorph, mandipropamid) and cyano-acetamide oximes (cymoxanil). In addition, multi-site fungicides such as mancozeb, folpet, chlorothalonil and copper formulations are important for disease control especially in mixtures or in alternation with site-specific fungicides. QoIs inhibit mitochondrial respiration, phenylamides the polymerization of r-RNA, whereas the mode of action of the other two site-specific classes is unknown but not multi-site. The use of site-specific fungicides has in many cases selected for resistant pathogen populations. QoIs are known to follow maternal, largely monogenic inheritance of resistance; they bear a high resistance risk for many but not all oomycetes. For phenylamides,
\end{abstract}

U. Gisi $(\bowtie) \cdot H$. Sierotzki

Research Biology, Syngenta Crop Protection, 4332 Stein, Switzerland

e-mail: ulrich.gisi@syngenta.com

U. Gisi

Institute of Botany, University of Basel,

4056 Basel, Switzerland inheritance of resistance is based on nuclear, probably monogenic mechanisms involving one or two semidominant genes; resistance risk is high for all oomycetes. The molecular mechanism of resistance to QoIs is mostly based on the G143A mutation in the cytochrome b gene; for phenylamides it is largely unknown. Resistance risk for CAA fungicides is considered as low to moderate depending on the pathogen species. Resistance to CAAs is controlled by two nuclear, recessive genes; the molecular mechanism is unknown. For QoIs and CAAs, resistance in field populations of $P$. viticola may gradually decline when applications are stopped.

Keywords CAA fungicides - Cytochrome b gene . G143A substitution - Inheritance of resistance . Monogenic resistance $\cdot$ Phenylamide fungicides . Phytophthora infestans Plasmopara viticola . QoI fungicides · Recessive resistance .

Segregation of resistance

\section{Introduction}

In spite of cultural practices and breeding for resistant cultivars, downy mildews are among the most devastating plant diseases. To avoid yield losses, disease control is required mainly by using chemical products. The economic importance of single downy mildew diseases (within Peronosporales and Sclerosporales) can be ranked according to the size of crop 
area treated with chemicals. In 2006, the sales value of the global fungicide market for the control of diseases caused by oomycetes was about US\$ 1.2 billion. By far the biggest segment of downy mildews worldwide is represented by Plasmopara viticola on grape (54\%), followed by Pseudoperonospora cubensis on cucurbits (12\%), Bremia lactucae on lettuce (8\%), Peronospora spp. on leek and onion (6\%), on tobacco (4\%), on field crops such as peas, brassicas and sugar beet (each 3\%) and on soybeans and corn (each 2\%), Pseudoperonospora humuli on hops and Plasmopara halstedii on sunflower (each 1\%), and the systemic pathogens Peronosclerospora and Sclerophthora spp. in corn (1\%) (Syngenta internal data). Not included in this list are pathogens of the Pythiales, especially Phytophthora spp., of which Phytophthora infestans on potato and tomato is the most predominant segment (about the same as the $P$. viticola segment). Phytophthora infestans is included in this review, because most fungicides controlling downy mildews are also active against Phytophthora spp., and the modes of action and mechanisms of resistance have often been studied in Phytopthora spp., which are easier to handle under laboratory and glasshouse conditions than the biotrophic downy mildews. Chemical control is the most effective measure currently used to protect crops from downy mildews. Surprisingly, the rather 'old' multi-site fungicides including dithiocarbamates (e.g. mancozeb), phthalimides (folpet), chloronitriles (chlorothalonil) and copper formulations account still for about $50 \%$ of the downy mildew fungicide market. Among the single-site fungicides, four chemical classes dominate the market: the Quinone outside inhibitors (QoIs; 'strobilurins', mainly azoxystrobin, famoxadone, fenamidone), the phenylamides (PAs, mainly mefenoxam), the carboxylic acid amides (CAAs; mainly dimethomorph, iprovalicarb, benthiavalicarb, mandipropamid) and the cyanoacetamid-oximes (cymoxanil). Smaller market shares are taken by phosphonates (mainly fosetyl-Al), dinitroanilines (fluazinam), carbamates (propamocarb) and plant defence inducers such as the benzothiadiazoles (BTH, acibenzolar-S-methyl/Bion).

For many decades, multi-site contact fungicides were the only compounds available for the control of downy mildews. Within the last 30 years, chemical control of downy mildews has undergone dramatic changes with the detection and introduction of singlesite fungicides such as cymoxanil (1976), fosetyl-Al
(1977), phenylamides (1977-1983), propamocarb (1978), CAAs (1992-2005) and QoIs (1996-2000; Gisi 2002). Generally, single site-fungicides act against a very specific step in the metabolism of pathogens and have only few side effects on other processes or non-target organisms. Most single-site fungicides penetrate into the leaf and are protected against wash-off by rain; some are also systemic and move into untreated parts of the plant. In contrast to multi-site fungicides, most single-site inhibitors bear a high intrinsic risk of causing the evolution of resistant pathogen sub-populations. This development is a common phenomenon in agricultural practice and is based on the selection of resistant individuals by the use of fungicides. However, a robust disease control programme will result also in a successful resistance management, because the probability of resistant survivors is smaller if the initial inoculum density is low. Therefore, all agronomic measures reducing disease pressure will also contribute to a reduced fungicide resistance risk. Effective resistance management and successful disease control are supported by the use of effective fungicide rates, alternation and mixtures of fungicides, appropriate spray intervals and an early onset of applications in the disease cycle.

\section{QoI fungicides}

QoI fungicides are inhibitors of mitochondrial respiration; they inhibit the electron transport at cytochrome $b$ (complex III) by binding to the Qo site, the ubiquinol oxidizing pocket, which is located at the positive, outerside of mitochondrial membranes. In the Qo pocket, the amino acid glutamic acid (Glu) at position 272 of the ef protein loop is responsible for binding to an oxygen moiety in the toxophore of the fungicide molecule $(\mathrm{O}-$ $\mathrm{H}-\mathrm{N}$ bridge; Gisi et al. 2002). The cytochrome b (cyt b) gene is the molecular target for QoI fungicides; it is located in the mitochondrial genome. Long before the introduction of agricultural QoI fungicides, resistance to QoI molecules (e.g. myxothiazol) was described as being based on several mutations in the cyt $b$ gene in a range of genera such as yeast (Saccharomyces), bacteria (Rhodobacter), protozoa (Paramecium), sea urchin, algae (Chlamydomonas) and mice (Di Rago et al. 1989; Geier et al. 1992; Degli-Esposti et al. 1993; Brasseur et al. 1996). However, it was not known which mutation would appear in plant pathogens. 
Sierotzki et al. (2000a, b) detected the G143A substitution (exchange of glycine by alanine at position 143) for the first time in QoI-resistant isolates of Blumeria (Erysiphe) graminis f.sp. tritici and Mycosphaerella fijiensis. This substitution is based on a single nucleotide polymorphism in the triplet at position 143 from GGT to GCT in the $c y t b$ gene. It was described in the following years in resistant isolates of many important plant pathogen species such as $P$. viticola, $P$. cubensis, Venturia inaequalis and Mycosphaerella graminicola (Heaney et al. 2000; Steinfeld et al. 2002; Gisi et al. 2002). It is associated with high levels of resistance (high resistance factors $\mathrm{RF}$ ) or 'complete' resistance which leads to a complete loss of disease control if QoIs are used as solo products. A second mutation, F129L (exchange of phenylalanine by leucine at position 129) was discovered in resistant isolates of a few pathogen species such as P. viticola (Sierotzki et al. 2005), Pythium aphanidermatum (Gisi et al. 2002) and Pyrenophora teres (Sierotzki et al. 2007), resulting in a 'partial', less pronounced resistance leading to reduced disease control. However, in $P$. infestans, Bremia lactucae, Peronospora spp. and in all rust genera (e.g. Puccinia, Uromyces, Phakopsora, Hemileia), no resistant isolates (and no mutations) were detected until now. For rusts, the lack of resistance (based on G143A) has been elucidated recently: an intron is present in $c y t b$ between positions 143 and 144 which has to be spliced for correct transcription and translation. The splice site recognition is based on a GGT triplet (De La Salle et al. 1982). If mutated from GGT to GCT, splicing will not occur resulting in a non-functional cytochrome b which is lethal (Grasso et al. 2006).

QoI resistance in P. viticola populations in Europe was first detected in 2000 (Heaney et al. 2000) and evolved quickly with a rapid increase of resistant isolates reaching a frequency in 2003 of $70 \%$ to $80 \%$ in France and about $30 \%$ in northwest Spain (Galicia; Fig. 1a,b). In the following years, the frequency of resistance remained more or less stable in the two countries (except for France with a further increase to about $90 \%$ in 2006). In the north of Italy and in Switzerland, frequencies reached high levels in certain areas, whereas in Portugal, Germany and Austria, they are still low (Sierotzki et al. 2008). Since the collected leaves always represented a bulk population, the measured frequency of resistance
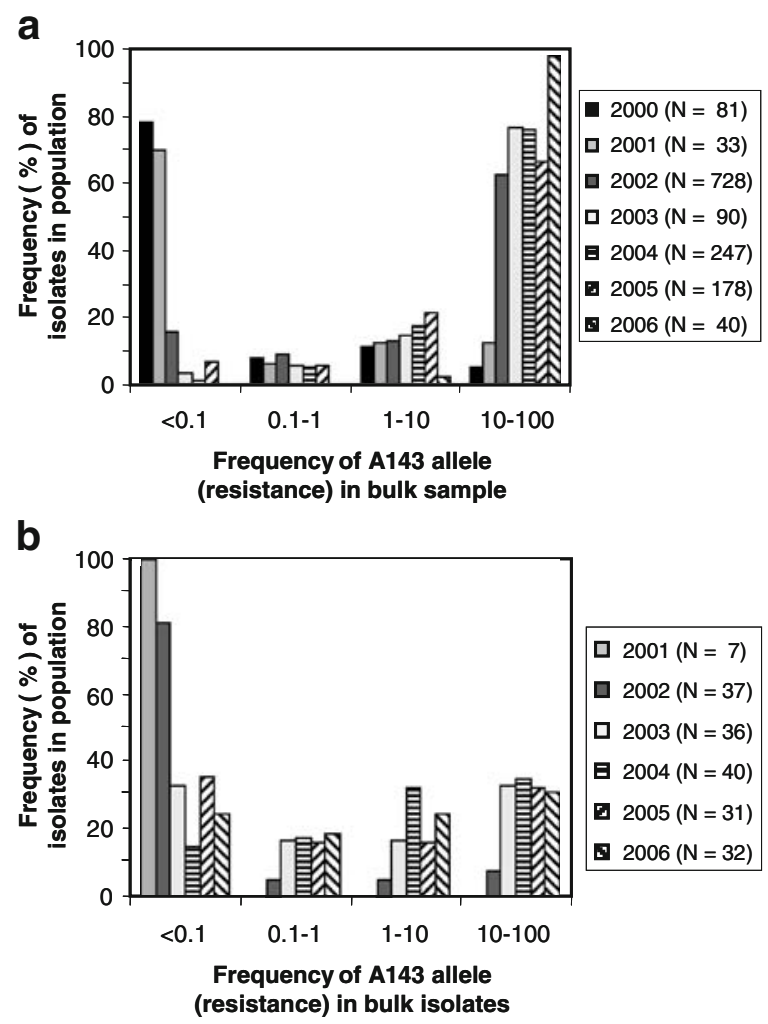

Fig. 1 Frequency of bulk isolates carrying the A143 allele (resistance to QoIs) in Plasmopara viticola populations collected in 2000 to 2006 in France (a) and in Spain (b; after Sierotzki et al. 2008)

(A143 allele in Q-PCR tests) is representative for the entire population at a specific vineyard. However, if single sporangiophore isolates are picked from these samples, they are always either completely sensitive (100\% G143 allele) or completely resistant (100\% A143 allele); heteroplasmic stages were never detected.

At a specific trial site in Brazil (Holambra), QoI treatments were carried out during several years until November 2000, when they were stopped for three years (2001-2003), re-started again in 2004, stopped in 2005 and started again in 2006. A decline of resistance was observed when QoI applications were stopped and a rapid increase when QoIs were used again (Fig. 2a,b; Sierotzki et al. 2008). This fluctuation of resistance resulting from the use strategy of QoIs might be based on a reduced fitness of QoI-resistant isolates, as it was described also by Heaney et al. (2000) and Genet et al. (2006). Similar declines of 
a

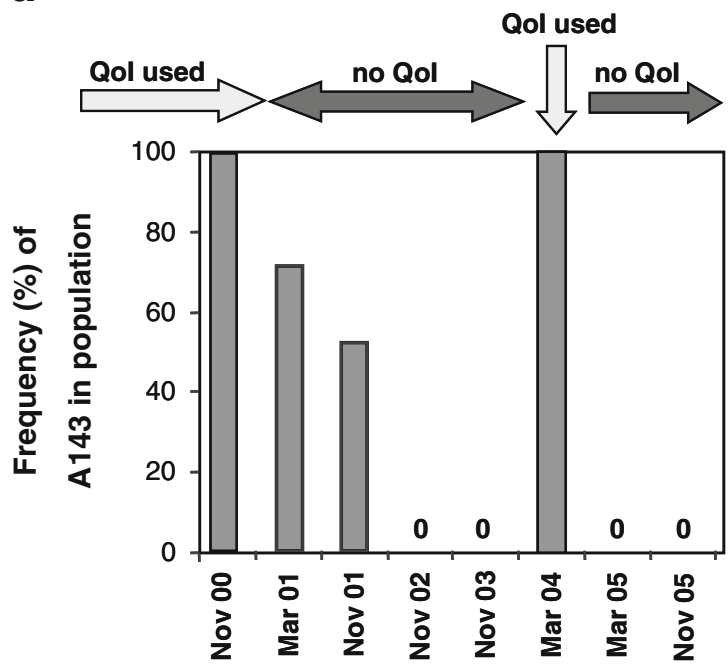

b

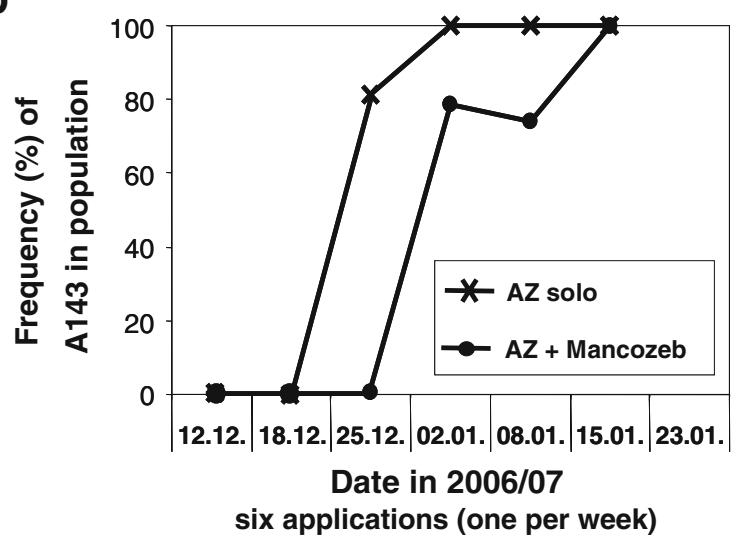

Fig. 2 Change in frequency of QoI-resistant isolates (carrying the A143 allele) in Plasmopara viticola populations as a result of different QoI usages at a trial site location (Holambra) in Brazil. a season-long applications (six treatments),stop and restart of azoxystrobin applications between 2000 and 2005; b six applications (one per week) of azoxystrobin (AZ) solo or in mixture with mancozeb in the 2006/2007 season (after Sierotzki et al. 2008)

resistance after QoI treatments were stopped have also been observed in oospore populations of $P$. viticola in some vineyards in Italy (Toffolatti et al. 2006) and in P. cubensis populations in glasshouses in Japan (Ishii 2003 personal communication).

In order to investigate the segregation pattern of QoI resistance, a sensitive $\mathrm{P} 2$ and a resistant P1 mating type single sporangiophore isolate (Scherer and Gisi 2006) were crossed by co-inoculating a 1:1 sporangial mixture onto grape leaves. After 14 days of incubation, plenty of oospores were produced in the leaves which were further incubated in dry conditions in the dark for another 8 weeks. Then, the rotted leaves with oospores were ground to powder, mixed with perlite and moistened with water for inducing oospore germination (Gisi et al. 2007b) as originally described for $P$. infestans (Rubin and Cohen 2006). Young grape leaves were incubated on top of the oospore/perlite mixture for 1 to 3 weeks until first sporangiophores appeared which were picked and propagated for producing F1 progeny isolates. Based on the mitochondrial origin of QoI resistance, a maternal inheritance of resistance $(0: 1$ or 1: 0 , depending whether resistance is in the male or female parent) was expected. Surprisingly, a segregation of resistance $\mathrm{r}: \mathrm{s}=8: 23$ (or $\sim 1: 3$ ) was observed; all resistant offspring carried the A143, the sensitive offspring the G143 allele (Fig. 3; Blum and Gisi 2008). Possible reasons for the unexpected segregation might be mitochondrial leakage, irregularities in the mating process or involvement of a recessive nuclear gene with epistatic regulation of the mitochondrial gene. The first possibility can be ruled out because no heteroplasmic stages were detected with Q-PCR; the second hypothesis is based on 'femaleness' of isolates (both parents may have the potential for oospore production) and was described for $P$. infestans (Judelson 1997). Thus, many basic features of the biology of $P$. viticola are still not well understood. Indeed, if inheritance of QoI resistance does not follow a $0: 1$ (in a single cross) or 1:1 pattern (in populations, assuming $\mathrm{P} 1$ : $\mathrm{P} 2$ ratio is about 1:1), evolution of resistance is not easy to predict, not even under 'controlled' conditions. The G143A mutation was obviously very rare in unselected populations of $P$. viticola prior to the use of QoI fungicides, but was quickly selected through the continuous use of these fungicides. It is an open question as to whether the G143A mutation (A143 allele) might be lost when QoI applications are stopped, as quickly as it appeared through selection. In addition, $P$. viticola is a pathogen with a high rate of sexual recombination and high genetic diversity resulting in many different genotypes every season (Scherer and Gisi 2006) but with a low migration rate resulting in local epidemics. Thus, resistance evolution might be driven mainly by 'local' processes (micro-climate, fungicide use strategies, disease pressure on different varieties). 
Fig. 3 Sensitivity to azoxystrobin (AZ; EC $50 \mathrm{mg}^{-1}$ ) of $\mathrm{F} 1$ progeny isolates derived from a cross between an AZ- sensitive and AZ-resistant parent (F0, black columns) in Plasmopara viticola (after Blum and Gisi 2008)

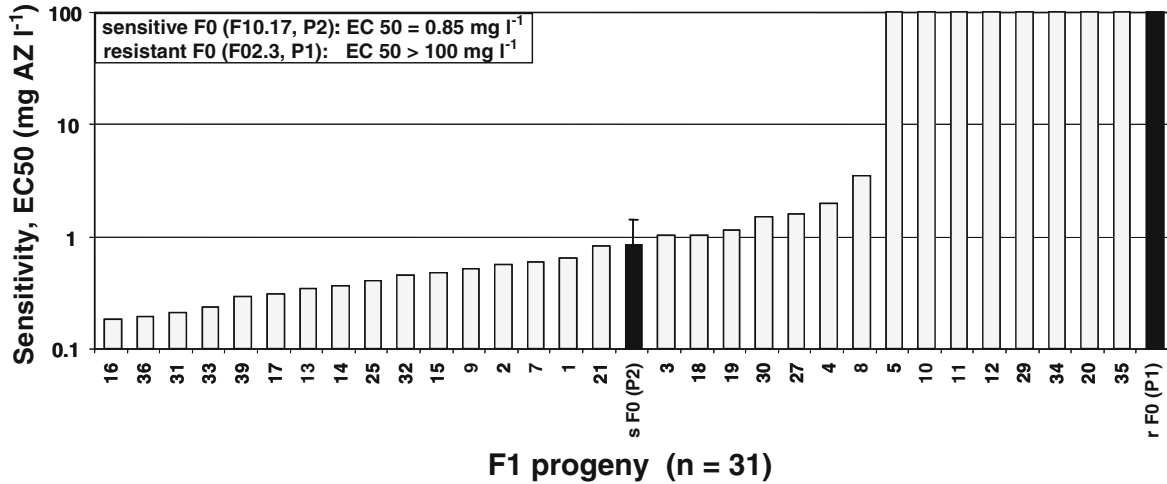

\section{Phenylamide fungicides}

Phenylamide fungicides such as mefenoxam (metalaxyl$M$ ), metalaxyl and benalaxyl inhibit ribosomal RNA synthesis, specifically RNA polymerization (polymerase complex I; Davidse 1995). The molecular target gene is unknown and no sequence data and no mutations are available, although phenylamides have been in use for more than 25 years. Resistance to phenylamides developed rather quickly after their introduction in many pathogen species of the oomycetes such as $P$. viticola, $P$. cubensis, Peronospora tabacina, B. lactucae and P. infestans (Table 1). Although resistance is widely spread nowadays, the frequency in populations rarely reaches $100 \%$; it fluctuates not only from year to year but also within the season. In French vineyards, resistance in P. viticola populations in 1987 to 1998 varied from 15 to $75 \%$ (Gisi 2002). In 2004, the proportion of sensitive, intermediate and resistant isolates was 35\%, $45 \%$, and 20\%, respectively (samples from France; Gisi et al. 2007b) and 15\%, 40\% and 45\%, respectively, in 2006 (samples from France, Italy, Spain, Germany; Fig. 4a). Resistance increased during the season (Fig. 4a) and was higher in mefenoxam-treated than untreated fields (Fig. 4b). The decrease of sensitive and the increase of intermediate and resistant isolates during the season was observed earlier over a period of four consecutive years (Fig. 4c) and seems to follow a seasonal pattern every year. Similar observations were also made for $P$. infestans populations (Gisi and Cohen 1996). Whether sexual recombination,

Table 1 Published cases of resistance to phenylamides in field populations of important pathogens in Peronosporales (first publication, in chronological order)

\begin{tabular}{lll}
\hline Pathogen species & Host plant & References \\
\hline Pseudoperonospora cubensis & cucurbits & Reuveni et al. 1980 \\
Phytophthora infestans & potato & Davidse et al. 1981 \\
Plasmopara viticola & grape & Staub and Sozzi 1981 \\
Peronospora tabacina & tobacco & Bruck et al. 1982 \\
Phytophthora cinnamomi & avocado & Darvas and Becker 1984 \\
Phytophthora parasitica & tobacco & Shew 1985 \\
Bremia lactucae & lettuce & Crute 1987 \\
Pythium spp. & turf, carrot & Sunders and Soika 1988; White et al. 1988 \\
Plasmopara halstedii & potato & Albourie et al. 1998 \\
Phytophthora erythroseptica & pea & Lambert and Salas 1994 \\
Peronospora viciae & ornamentals & Falloon et al. 2000 \\
Pythium spp. & onion & Moorman and Kim 2004 \\
Peronospora destructor & & Wright 2004 \\
\hline
\end{tabular}


Fig. 4 Sensitivity to mefenoxam (sensitive, intermediate, resistant; proportion of isolates in (a) and (c), EC 50 in (b)) of Plasmopara viticola isolates collected in France, Italy, Spain and Germany in 2006 $(N=49)$ early, mid and late in the season (a) and from mefenoxam-untreated or treated fields (b), and in France (Armagnac area) in four consecutive years (1997 to 2000, represented as the average of the four years) early $(N=132)$, $\operatorname{mid}(N=85)$ and late $(N=$ $110)$ in the season
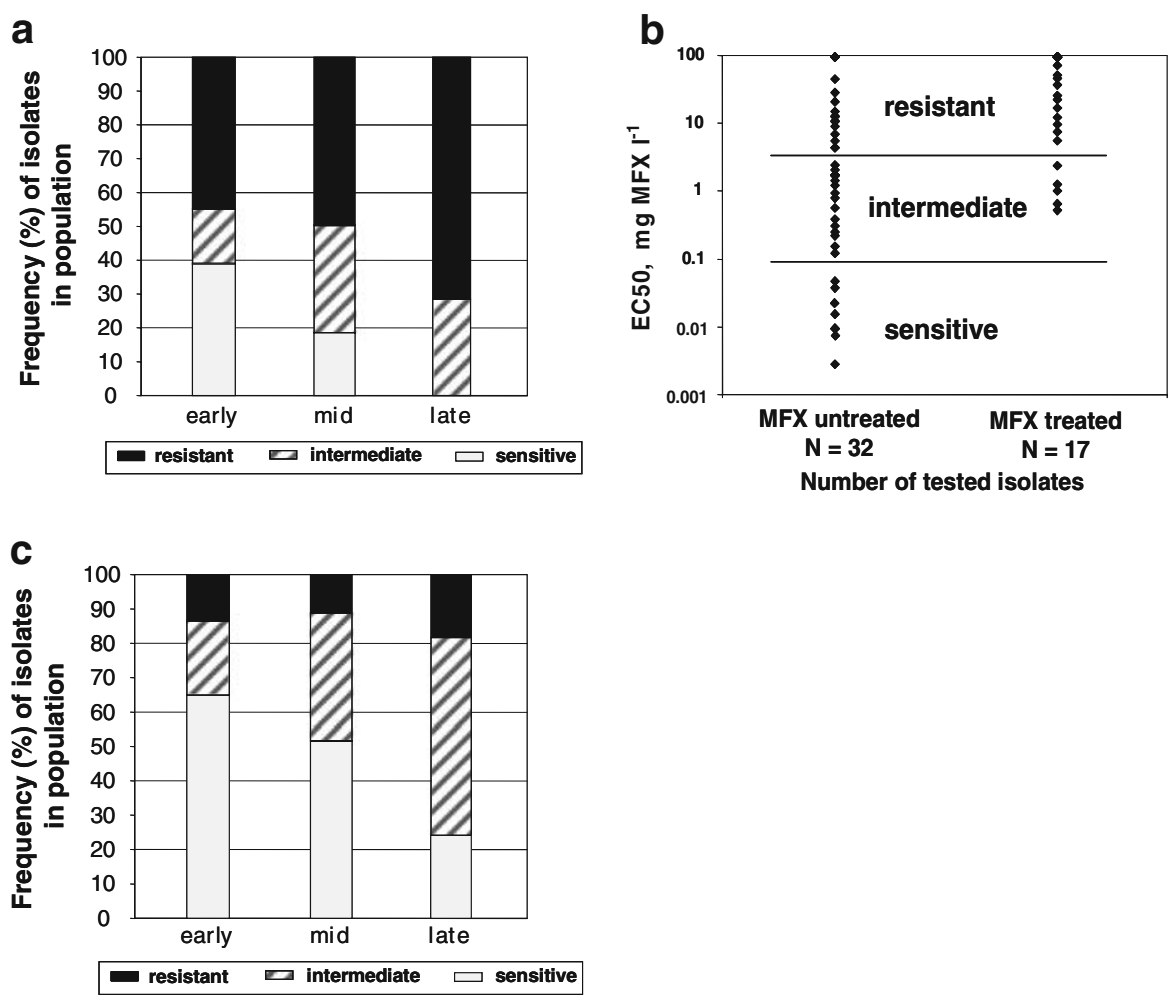

pathogenic fitness and/or over-seasoning capacity of resistant isolates play a major role for these dynamics is still to be elucidated.

Inheritance of phenylamide resistance in the F1 progeny was studied in crosses of $P$. viticola (Fig. 5a) and $P$. infestans (Fig. 5b) by co-inoculation of mefenoxam-sensitive and resistant parents according to the method described for QoI fungicides (Fig. 3). The segregation pattern of phenylamide resistance in $P$. infestans corresponded to the expected Mendelian mechanisms for inheritance based on one semidominant gene: all F1 progeny isolates were intermediates (Fig. 5b, Knapova et al. 2002). However, in $P$. viticola the segregation pattern was somewhat unexpected (Fig. 5a) with a proportion of r:i:s= 21:8:2 (Blum and Gisi 2008). In this experiment, the sensitive parent may be considered as 'truly sensitive' or as intermediate (depending on categorization of EC50 value in the bioassay). The segregation of resistance in the $\mathrm{F} 1$, based on one semi-dominant gene in the resistant parent should result either in an entirely intermediate progeny (if the other parent is considered as sensitive) or in $r: i=1: 1$ (if the other parent is considered as intermediate). The observed segregation pattern does not fit to either of the expected segregation. If resistance is based on one dominant gene, the expected segregation would differ even more from the observed pattern. Since for $P$. viticola, no other data on resistance segregation in the F1 are available in the literature, it remains unclear whether the genetic background of mefenoxam resistance is different in $P$. viticola compared to $P$. infestans, or whether sexual recombination and oospore production follows some yet unknown modifications in $P$. viticola as was speculated to occur for the inheritance of QoI resistance (see above). Similarly, a distorted segregation pattern was also described in $P$. infestans when oospores were produced in planta as compared to in agar cultures (Van der Lee et al. 2004; Rubin and Cohen 2006). In addition, the segregation pattern of phenylamide resistance in P. viticola was described for F2 progeny by Gisi et al. (2007b): a proportion of s:i:r=1:2.7:2 was observed which was considered to be based on one semidominant gene affected by minor genes as described for P. infestans (Judelson and Roberts 1999). In 
Fig. 5 Sensitivity to mefenoxam (MFX; EC $50 \mathrm{mg}^{-1}$ ) of $\mathrm{F} 1$ progeny isolates derived from a cross between an MFX-sensitive and MFX-resistant parent (F0, black columns) of a Plasmopara viticola (after Blum and Gisi 2008) and of b Phytophthora infestans (after Knapova et al. 2002)
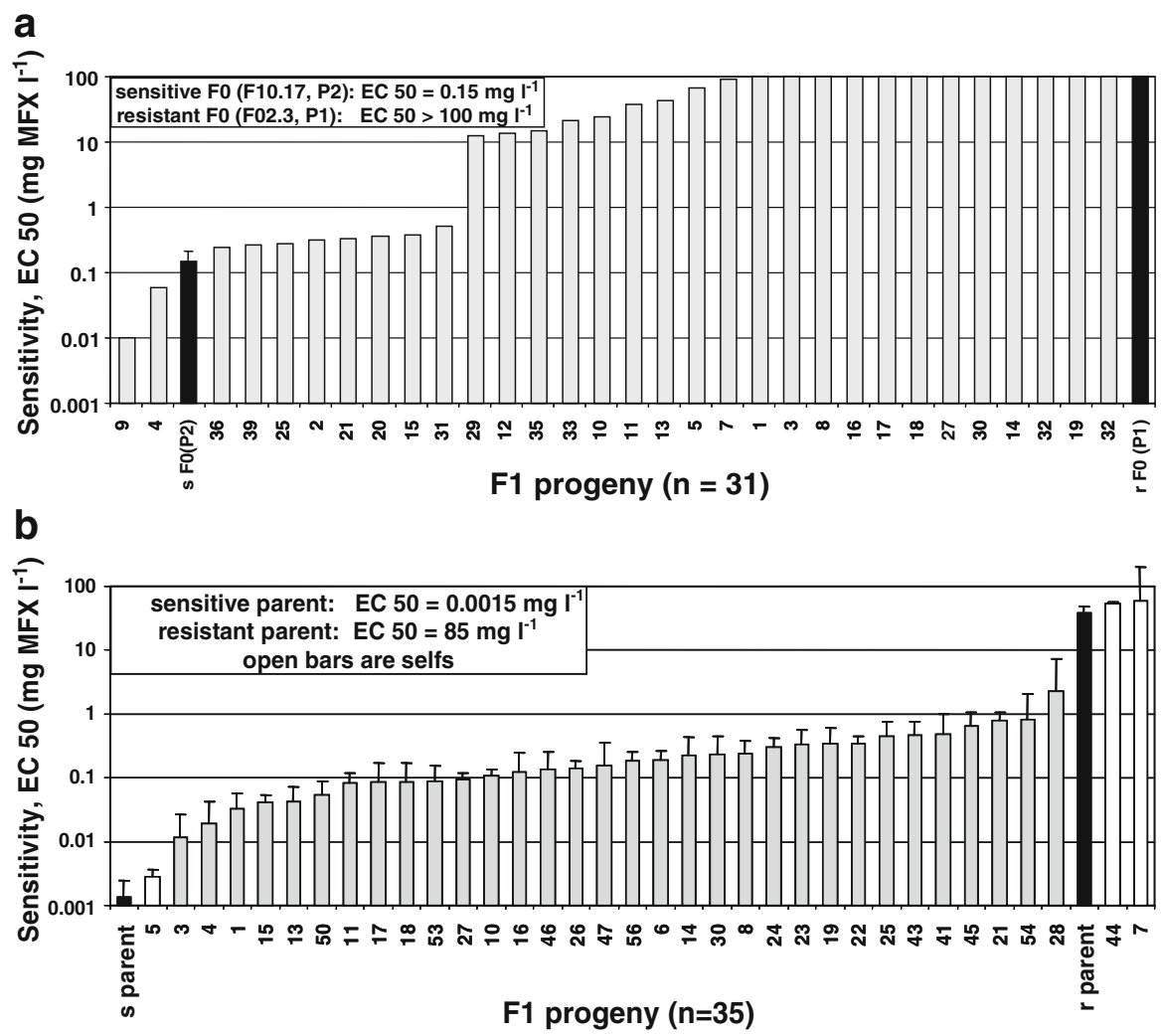

summary, the risk of resistance for phenylamide fungicides is considered as high, the evolution as fast with a certain stabilization effect over time, and a reappearance of sensitivity in unselected populations after sexual recombination.

\section{CAA fungicides}

The biochemical mode of action of CAA fungicides (including dimethomorph, flumorph, iprovalicarb, benthiavalicarb, mandipropamid) is still speculative; potential targets are phospholipid biosynthesis (Griffiths et al. 2003) and cell wall deposition (Jende et al. 2002; Cohen and Gisi 2007; Gisi et al. 2007a). Although CAAs may interfere with cell membranes, it is doubtful whether the observed effects on phosphocholinetransferase, the last step in the Kennedy pathway of lecithin biosynthesis (Griffiths et al. 2003) can be considered as primary effects caused by CAA fungicides. Similarly, the observed changes in cell wall architecture and deposition during germination of cystospores (Jende et al. 2002) may be a secondary effect, because some of the key enzymes of cell wall biosynthesis such as glucanases and synthases of $\beta-1,3$ glucans and cellulose may not be inhibited directly (Mehl and Buchenauer 2002; Gisi et al. 2007a). Most likely, the target site for CAA fungicides may be membrane-bound at the interface between plasmalemma and cell wall (Syngenta internal data). So far, the target gene(s) have not been identified and no mutations conferring resistance are known, although CAAresistant field isolates of $P$. viticola are available.

In spite of an intensive monitoring programme, no resistant isolates have been detected in $P$. infestans populations (Cohen et al. 2007; FRAC CAA working group reports, www.frac.info), although CAA fungicides (dimethomorph) have been used commercially for more than 10 years. Also, enforced selection experiments and mutagenesis did not yield isolates in $P$. infestans with stable resistance to CAAs (Bagirova et al. 2001; Stein and Kirk 2004; Yuan et al. 2006; Cohen et al. 2007; Rubin et al. 2008). Therefore, resistance risk for CAA fungicides in $P$. infestans can be considered as low. The entire genus Pythium is insensitive to CAA fungicides; therefore, there are no resistance issues for CAAs in this genus. However, CAA-resistant isolates have been detected in $P$. 
viticola populations for several years in some regions of France and Germany (Gisi et al. 2007b), but no serious product failures were reported. Mean resistance factors are often $>300$, and resistant isolates are stable when transferred onto untreated grape leaves (Gisi et al. 2007b). Also, in P. cubensis, resistant isolates have recently been detected in a few trial site locations, one each in South Korea, Israel and USA (FRAC CAA working group reports, www.frac.info) and in China (Zhu et al. 2007). When a CAAsensitive and CAA-resistant single sporangiophore isolate of $P$. viticola were crossed (method see above), resistance segregated in the $F 1$ in a $0: 1$ (entire $F 1$ progeny sensitive) and in the F2 in a 1:9 pattern, suggesting that two recessive nuclear genes are involved in CAA resistance (Gisi et al. 2007b). Based on this segregation pattern, resistance risk for CAA fungicides in $P$. viticola was estimated to be moderate.

The evolution of resistance to CAA fungicides in $P$. viticola populations was followed over several years at four different trial sites (Les Barges and Stein in Switzerland, Marsillargues and Estillac in France) in response to different spray programmes (treatments stopped or applications as solo product or in mixture with multi-site fungicides; Fig. 6). At locations with fully resistant initial populations (resulting from season-long selection with recommended rates during several years), resistance clearly declined (in some cases to zero) within 2 years after mandipropamid applications were stopped. At locations with low proportions of CAA resistance at the beginning of the season, six applications (full recommended rates) caused a more rapid increase of resistance when the product was used solo as compared to when used in mixture (with Folpet). Interestingly, the proportion of resistance in the populations at the Stein and Estillac sites was lower at the beginning of the season than at the end of the previous season (Fig. 6). These observations suggest that CAA-resistant isolates of $P$. viticola may be less fit in the absence of selection pressure than sensitive isolates. The decline of resistance in the absence of CAA treatments is an additional element supporting the classification of resistance to be moderate for CAAs in P. viticola (as compared to high for QoI and phenylamide fungicides; www.frac.info).

\section{Other fungicide classes against oomycetes}

The multi-site inhibitors such as copper formulations, dithiocarbamates like mancozeb, phthalimides like folpet and chloroisophthalonitriles like chlorothalonil are non-systemic, preventive fungicides forming a protectant barrier at the surface of the plant against pathogens, and inhibit pathogen development prior to penetration into the tissue. They interact mostly unspecifically with many biochemical steps in the pathogen metabolism, such as the formation of
Fig. 6 Evolution of resistance to CAA fungicides at four trial sites during the season and over several years as a result of season-long application of mandipropamid (six to eight applications) as a solo product or in mixtures with multi-site fungicides and after treatments were stopped
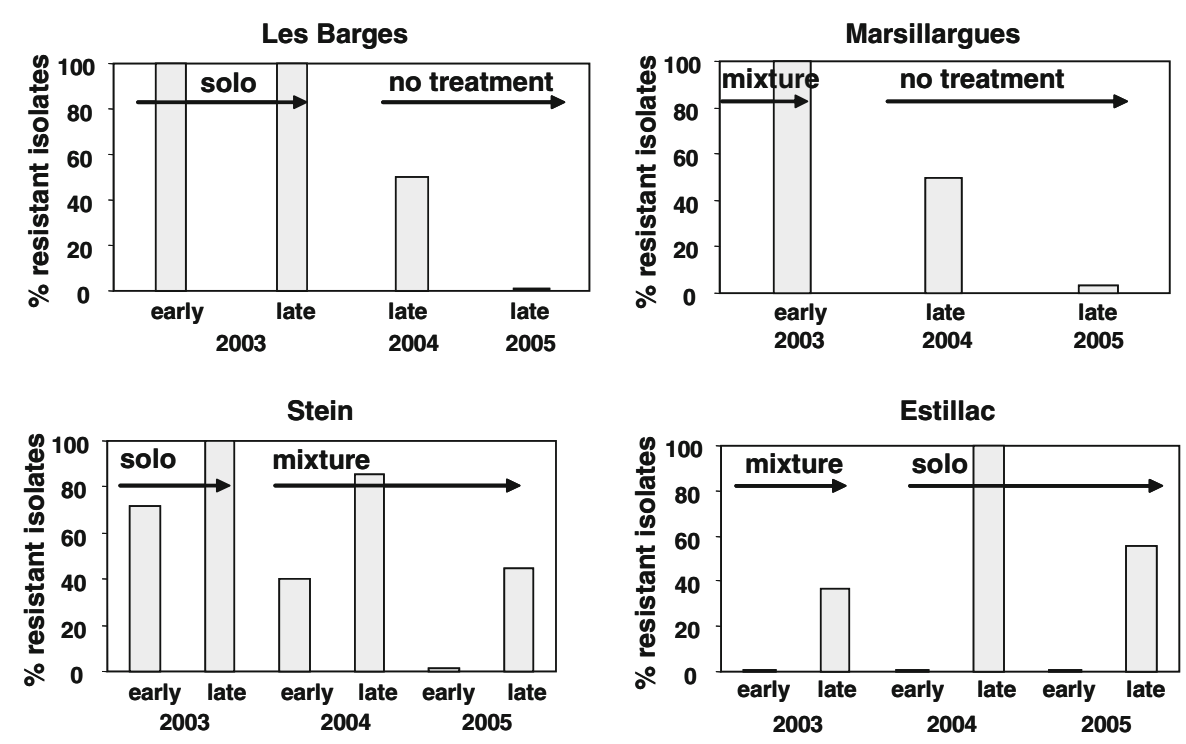
complexes with enzymes possessing sulphydrylgroups (Gisi 2002). As a consequence, the enzymes are inactivated leading to a general disruption of metabolism and cell integrity. Based on the multi-site mode of action, resistance to such inhibitors has never developed and is unlikely to evolve. Multi-site fungicides are important elements in spray programmes (about $50 \%$ of the total oomycete fungicide market) either as stand alone products or in mixtures with single-site fungicides to improve their activity and to delay resistance evolution.

Based on its short persistence, the systemic cyanoacetamide oxime fungicide cymoxanil is used against oomycetes always in mixtures with multi-site fungicides. The biochemical mode of action of cymoxanil is unknown. Reduced sensitive (or resistant) isolates have been reported in field populations of $P$. viticola (but not of $P$. infestans) in several vineyards of Italy and France (Gullino et al. 1997; Genet and Vincent 1999). Depending on the proportion of resistance in populations, the curative activity of cymoxanil can be significantly reduced. The dinitroaniline fungicide fluazinam is an uncoupler of phosphorylation from electron transport by disrupting the proton gradient; as a consequence, ATP production is blocked (Gisi 2002). Resistance in field populations of oomycetes has never been reported. The carbamate fungicide propamocarb is reported to affect the permeability of cell membranes; as a consequence, leakage of cell components has been observed, but the precise biochemical mode of action is not well understood. Field isolates resistant to propamocarb have been detected in Pythium species (Moorman and Kim 2004). Within the chemical class of phosphonates, fosetyl-Al and its breakdown product phosphorous acid $\left(\mathrm{H}_{3} \mathrm{PO}_{3}\right)$ are readily taken up by plant tissue and translocated systemically within the phloem (symplastically). Fosetyl-Al may have an indirect effect against downy mildews by stimulating the plant defence reactions; but also a direct antifungal activity has been reported (change in phosphorylated sugar content and cell wall composition; Gisi 2002). Nevertheless, the primary site of action is not known, and resistant isolates in field populations have never been detected. For 'true' plant defence inducers such as acibenzolar- $S$-methyl (Bion), it is generally assumed that pathogens cannot develop resistance very easily, because several mechanisms would have to be overcome (Gisi 2002).

\section{Conclusions}

Resistance evolution depends on the specific action of the fungicide (biochemical and molecular mechanisms), the agronomic usage of the fungicide and the pathogen biology. These parameters have been used by FRAC for resistance risk assessment for all chemical classes ('FRAC grid' in Monograph 1, FRAC classification lists, www.frac.info). In $P$. viticola, fungicide resistance has emerged quite quickly (within a few years) after product introduction for almost every chemical class of single-site fungicides (phenylamides, cymoxanil, QoIs, CAAs), whereas in P. infestans it emerged only for phenylamides (Kuck and Russell 2006). Therefore, resistance risk assessment has to be carried out carefully and for each single pair of fungicide and pathogen species. In order to delay resistance evolution and ensure robust disease control for as long as possible, all available chemical classes of fungicides such as QoIs, phenylamides, CAAs, cyanoacetamide-oximes, phosphonates and multi-site fungicides should be integrated in a spray programme, either in sequence and/or in mixtures. Fungicide applications should start before or at the onset of the epidemics; the recommended rates and spray intervals have to be strictly followed and adapted to the local disease and weather conditions.

Acknowledgements We acknowledge the excellent experimental contributions of Maya Waldner, Regula Frey, Dominique Edel, Noemy Kraus and Mathias Blum.

\section{References}

Albourie, J. M., Tourville, J., \& Tourviellie De Labrouhe, D. (1998). Resistance to metalaxyl in isolates of the sunflower pathogen Plasmopara halstedii. European Journal of Plant Pathology, 194, 235-242.

Bagirova, S. F., Li, A. Z., Dolgova, A. V., Elansky, S. N., Shaw, D. S., \& Dyakov, T. (2001). Mutants of Phytophthora infestans resistant to dimethomorph fungicide. Journal of Russian Phytopathological Society, 2, 19-24.

Blum, M., \& Gisi, U. (2008). Inheritance of resistance in Plasmopara viticola. In H.W. Dehne, U. Gisi, K.H. Kuck, P.E. Russell \& H. Lyr (Eds.), Modern Fungicides and Antifungal Compounds $V$. BCPC, Alton (in press).

Brasseur, G., Saribas, A. S., \& Daldal, F. (1996). A compilation of mutations located in the cytochrome b subunit of the bacterial and mitochondrial bc1 complex. Biochimica and Biophysica Acta, 1275, 61-69.

Bruck, R., Gooding Jr., G. V., \& Main, C. E. (1982). Evidence for resistance to metalaxyl in isolates of Peronospora hyoscyami. Plant Disease, 66, 44-45. 
Cohen, Y., \& Gisi, U. (2007). Different activity of carboxylic acid amide fungicides against various development stages of Phytophthora infestans. Phytopathology, 97, 12741283.

Cohen, Y., Rubin, E., Hadad, T., Gotlieb, D., Sierotzki, H., \& Gisi, U. (2007). Sensitivity of Phytophthora infestans to mandipropamid and the effect of enforced selection pressure in the field. Plant Pathology, 56, 836-842.

Crute, I. R. (1987). The occurrence, characteristics, distribution, genetics and control of a metalaxy-resistant genotype of Bremia lactucae in the United Kingdom. Plant Disease, 71, 763-767.

Darvas, J. M., \& Becker, O. (1984). Failure to control Phytophthora cinnamomi and Pythium splendens with metalaxyl after its prolonged use. Citrus and Subtropical Fruit Journal, 603, 9-11.

Davidse, L. C. (1995). Phenylamide fungicides: biochemical action and resistance. In H. Lyr (Ed.), Modern Selective Fungicides (2nd ed., pp. 347-354). Jena: Gustav Fischer.

Davidse, L. C., Looijeu, D., Turkenstein, L. J., \& Van Der Wal, D. (1981). Occurrence of metalaxyl resistant strains of potato blight in Dutch potato fields. The Netherlands Journal of Plant Pathology, 87, 65-68.

Degli-Esposti, M., De Vries, S., Crimi, M., Ghelli, A., Patarnello, T., \& Meyer, A. (1993). Mitochondrial cytochrome b: evolution and structure of the protein. Biochimica and Biophysica Acta, 1143, 243-271.

De La Salle, H., Jacq, C., \& Slonimski, P. P. (1982). Critical sequences with mitochondrial introns: pleiotropic mRNA maturase and cis-dominant signals of the box intron controlling reductase and oxidase. Cell, 28, 721-732.

Di Rago, J. P., Coppée, J. Y., \& Colson, A. M. (1989). Molecular basis for resistance to myxothiazol, mucidin (strobilurin A) and stigmatellin. Journal of Biological Chemistry, 264, 14543-14548.

Falloon, R. E., Follas, G. B., Butler, R. C., \& Goulder, D. S. (2000). Resistance in Peronospora viciae to phenylamide fungicides: reduced efficacy of seed treatments of pea (Pisum sativum) and assessment of alternatives. Crop Protection, 19, 313-325.

Geier, B. M., Schägger, H., Brandt, U., Colson, A. M., \& Von Jagow, G. (1992). Point mutation in cytochrome b of yeast ubihydroquinone-cytochrome-c-oxidoreductase causing myxothiazol resistance and facilitated dissociation of the iron-sulfur subunit. European Journal of Biochemistry, 208, 375-380.

Genet, J. L., Jaworska, G., \& Deparis, F. (2006). Effect of dose rate and mixtures of fungicides on selection for QoI resistance in populations of Plasmopara viticola. Pest Management Science, 62, 188-194.

Genet, J. L., \& Vincent, O. (1999). Sensitivity of European Plasmopara viticola populations to cymoxanil. Pesticide Science, 55, 129-136.

Gisi, U. (2002). Chemical control of downy mildews. In P. T. N. Spencer-Phillips, U. Gisi, \& A. Lebeda (Eds.), Advances in downy mildew research (pp. 119-159). Dordrecht: Kluwer Academic.

Gisi, U., \& Cohen, Y. (1996). Resistance to phenylamide fungicides: A case study with Phytophthora infestans involving mating type and race structure. Annual Review of Phytopathology, 34, 549-572.
Gisi, U., Lamberth, C., Mehl, A., \& Seitz, T. (2007a). Carboxylic Acid Amide (CAA) Fungicides. In W. Krämer, \& U. Schirmer (Eds.) Modern crop protection compounds (pp. 651-674). Weinheim: Wiley.

Gisi, U., Sierotzki, H., Cook, A., \& McCaffery, A. (2002). Mechanisms influencing the evolution of resistance to Qo inhibitor fungicides. Pest Management Science, 58, 859-867.

Gisi, U., Waldner, M., Kraus, N., Dubuis, P. H., \& Sierotzki, H. (2007b). Inheritance of resistance to carboxylic acid amide (CAA) fungicides in Plasmopara viticola. Plant Pathology, 56, 199-208.

Griffiths, R. G., Dancer, J., O’Neill, E., \& Harwood, J. L. (2003). A mandelamide pesticide alters lipid metabolism in Phytophthora infestans. New Phytologist, 158, 345353.

Grasso, V., Palermo, S., Sierotzki, H., Garibaldi, A., \& Gisi, U. (2006). Cytochrome b gene structure and consequences for resistance to Qo inhibitor fungicides in plant pathogens. Pest Management Science, 62, 465-472.

Gullino, M. L., Mescalchin, E., \& Mezzalama, M. (1997). Sensitivity to cymoxanil in populations of Plasmopara viticola in northern Italy. Plant Pathology, 46, 729-736.

Heaney, S. P., Hall, A. A., Davies, S. A., \& Olaya, G. (2000). Resistance to fungicides in the QoI-STAR cross-resistance group: current perspectives. Brighton Crop Protection Conference, 2, 755-762.

Jende, G., Steiner, U., \& Dehne, H. W. (2002). Microscopical characterization of fungicidal effects on infection structures and cell wall formation of Phytophthora infestans. In H. W. Dehne, U. Gisi, K. H. Kuck, P. E. Russell, \& H. Lyr (Eds.), Modern Fungicides and Antifungal Compounds III (pp. 83-90). Bonn: AgroConcept.

Judelson, H. S. (1997). Expression and inheritance of sexual preference and selfing potential in Phytophthora infestans. Fungal Genetics and Biology, 21, 188-197.

Judelson, H. S., \& Roberts, S. (1999). Multiple loci determining insensitivity to phenylamide fungicides in Phytophthora infestans. Phytopathology, 89, 754-760.

Knapova, G., Schlenzig, A., \& Gisi, U. (2002). Crosses between isolates of Phytophthora infestans from potato and tomato and characterization of F1 and F2 progeny for phenotypic and molecular markers. Plant Pathology, 51, 698-709.

Kuck, K. H., \& Russell, P. E. (2006). FRAC: Combined resistance risk assessment. In R. J. Bryson, F. J. Burnett, V. Foster, B. A. Fraaije \& R. Kennedy (Eds.), Fungicide Resistance: are we winning the battle but losing the war?, AAB Conference Proceedings, Aspects of Applied Biology 78, 3-10, Edinburgh, UK.

Lambert, D. H., \& Salas, B. (1994). Metalaxyl insensitivity of Phytophthora erythroseptica isolates causing pink rot of potato in Maine. Plant Disease, 78, 1010.

Mehl, A., \& Buchenauer, H. (2002). Investigations of the biochemical mode of action of iprovalicarb. In $\mathrm{H}$. W. Dehne, U. Gisi, K. H. Kuck, P. E. Russell, \& H. Lyr (Eds.), Modern Fungicides and Antifungal Compounds III (pp. 75-82). Bonn: AgroConcept.

Moorman, G. W., \& Kim, S. H. (2004). Species of Pythium from greenhouses in Pennsylvania exhibit resistance to propamocarb and mefenoxam. Plant Disease, 88, 630632. 
Reuveni, M., Eyal, H., \& Cohen, Y. (1980). Development of resistance to metalaxyl in Pseudoperonospora cubensis. Plant Disease, 64, 1108-1109.

Rubin, E., \& Cohen, Y. (2006). An improved method for infecting tomato leaves or seedlings with oospores of Phytophthora infestans used to investigate F1 progeny. Plant Disease, 90, 741-749.

Rubin, E., Gotlieb, D., Gisi, U., \& Cohen, Y (2008). Mutagenesis of Phytophthora infestans for resistance against carboxylic acid amide (CAA) and phenylamide fungicides. Plant Disease, 92 (in press).

Sanders, P. L., \& Soika, M. D. (1988). Metalaxyl resistance frequency in overwintering populations of Pythium aphanidermatum from metalaxyl control failure sites. Phytopathology, 78, 1510.

Scherer, E., \& Gisi, U. (2006). Characterization of genotype and mating type in European isolates of Plasmopara viticola. Journal of Phytopathology, 154, 489-495.

Shew, H. D. (1985). Response of Phytophthora parasitica var. nicotianae to metalaxyl exposure. Plant Disease, 69, 559562.

Sierotzki, H., Frey, R., Wullschleger, J., Palermo, S., Karlin, S., Godwin, J., et al. (2007). Cytochrome b gene sequence and structure of Pyrenophora teres and P. tritici-repentis and implications for QoI resistance. Pest Management Science, 63, 225-233.

Sierotzki, H., Kraus, N., Assemat, P., Stanger, C., Cleere, S., Windass, J., et al. (2005). Evolution of resistance to QoI fungicides in Plasmopara viticola populations in Europe. In H. W. Dehne, U. Gisi, K. H. Kuck, P. E. Russell, \& H. Lyr (Eds.), Modern Fungicides and Antifungal Compounds IV (pp. 73-80). Alton: BCPC.

Sierotzki, H., Kraus, N., Fernandes, N., \& Gisi, U. (2008). Dynamics of QoI resistance in Plasmopara viticola. In $\mathrm{H}$. W. Dehne, U. Gisi, K. H. Kuck, P. E. Russell \& H. Lyr (Eds.), Modern Fungicides and Antifungal Compounds V, BCPC, Alton, (in press).

Sierotzki, H., Parisi, S., Steinfeld, U., Tenzer, I., Poirey, S., \& Gisi, U. (2000a). Mode of resistance to respiration inhibitors at the cytochrome bc1 enzyme complex of
Mycosphaerella fijiensis field isolates. Pest Management Science, 56, 833-841.

Sierotzki, H., Wullschleger, J., \& Gisi, U. (2000b). Point-mutation in cytochrome $\mathrm{b}$ gene conferring resistance to strobilurin fungicides in Erysiphe graminis f.sp. tritici field isolates. Pesticide Biochemistry and Physiology, 68, 107-112.

Staub, T., \& Sozzi, D. (1981). Résistance au métalaxyl en pratique et les conséquences pour son utilisation. PhytiatriePhytopharmacie, 30, 283-291.

Stein, J. M., \& Kirk, W. W. (2004). The generation and quantification of resistance to dimethomorph in Phytophthora infestans. Plant Disease, 88, 930-934.

Steinfeld, U., Sierotzki, H., Parisi, S., \& Gisi, U. (2002). Comparison of resistance michanisms to strobilurin fungicides in Venturia inaequalis. In H. W. Dehne, U. Gisi, K. H. Kuck, P. E. Russell, \& H. Lyr (Eds.), Modern Fungicides and Antifungal Compounds III (pp. 167-176). Bonn: AgroConcept.

Toffolatti, S., Serrati, L., Sierotzki, H., Gisi, U., \& Vercesi, A. (2006). Assessment of QoI resistance in Plasmopara viticola oospores. Pest Management Science, 63, 194-201.

Van der Lee, T. H., Testa, A., Robold, A., van't Klooster, J., \& Govers, F. (2004). High-density genetic linkage maps of Phytophthora infestans reveal trisomic progeny and chromosomal rearrangements. Genetics, 167, 1643-1661.

White, J. G., Stanghellini, M. E., \& Ayoubi, L. M. (1988). Variation in the sensitivity to metalaxyl of Pythium spp. isolated from carrot and other sources. Annals of Applied Biology, 113, 269-278.

Wright, P. J. (2004). Resistance of Peronospora destructor (onion downy mildew) to metalaxyl fungicides. Proceedings of New Zealand Plant Protection Conference, 57, 347.

Yuan, S. K., Liu, X. L., Si, N. G., Dong, J., Gu, B. G., \& Jiang, H. (2006). Sensitivity of Phytophthora infestans to flumorph: In vitro determination of baseline sensitivity and the risk of resistance. Plant Pathology, 55, 258-263.

Zhu, S. S., Liu, X. L., Wang, Y., Wu, X. H., Liu, P. F., Li, J. Q., et al. (2007). Resistance of Pseudoperonospora cubensis to flumorph on cucumber in plastic houses. Plant Pathology, 56, 967-975. 